\title{
Impact of Broadband Internet on the Economic Growth of the Russian Regions
}

\author{
Imasheva I.Y. \\ Department of Economics \\ V. G. Timiryasov Innovative University \\ Kazan, Russia \\ ilya.mechta@bk.r
}

\author{
Kramin T.V. \\ V. G. Timiryasov Innovative University \\ Kazan, Russia \\ Federal research center of physical culture and sports, \\ Moscow, Russia \\ kramint@mail.ru
}

\begin{abstract}
The role of digital economy factors in economic growth is of special interest today. One of the mechanism of their impact is the broadband Internet, including information-legal platforms, web-sites, and social networks. Advancement of the broadband Internet facilitates digital transformation and forming economic links. To develop digital economy in the Russian regions it is essential to research the broadband Internet and check the hypothesis of the presence and character of its impact on economic growth. The article presents a review of scientific results which confirm the presence of the broadband Internet impact on economic growth of the Russian regions. To estimate the impact of the broadband Internet on economic growth of the Russian regions, the authors used the regression model of economic growth by $\mathbf{R}$. Solow, based on Cobb-Douglas production function, introducing the broadband Internet into it as an additional factor of creating the gross regional product. Economic modeling helped to identify and mathematically prove the impact of the broadband Internet on the gross regional product of the Russian regions in 2010-2016. In particular, it was shown that there is constant positive elasticity of the actual gross regional product of the Russian regions in accordance with the model variables characterizing the development of the broadband Internet in them. The obtained results allow concluding that it is necessary to improve and accelerate the broadband Internet as one of the factors of facilitating economic growth at the regional level.
\end{abstract}

Keywords-regression model; Cobb-Douglas production function; economic growth; broadband Internet; regression model of economic growth by $R$. Solow; regional economy.

\section{INTRODUCTION}

Improving the broadband Internet is an important provision of the EU Digital Agenda for Europe program, as well as in many industrial countries. The European Commission objective is to provide sustainable economic and social relationships through a Digital Single Market with the help of speedy and high-speed Internet and compatible applications
Apparently, for the states promoting such cost-intensive network deployment, the main indicator is the expectation that high-speed broadband connections will significantly stimulate economic growth. However, there is an opposite opinion; for example, R. Gordon asserts that the global economy has already derived benefits from the Internet and web revolution, hence the revival of productivity which occurred in the late 1990-s can hardly be repeated [1].

L.-H. Roller and L. Waverman analyzed how investments into telecommunications influence economic growth [2]. Their approach allowed revealing interconnections between the performance of telecommunications sector and economy as a whole. L.-H. Roller and L. Waverman found that telecommunications increased the economic growth of an OECD state by about one third during the studied period.

The fruitful work by L.-H. Roller and L. Waverman stimulated other researches in this sphere. Most of them confirmed a strong positive impact of the broadband connections on economic growth. In particular, P. Koutroumpis estimated data of 15 EU countries for 20032006 and showed that a $10 \%$ increase of penetration factor for a particular year increases GDP by about 3\% [3]. Later, N. Czernich et al. complemented the per capita GDP growth equation with a model of technological diffusion to form instrumental variables [4]. Their work showed that in 24 OECD countries in 1996-2007 a $10 \%$ increase of broadband connections penetration increases per capita GDP by 0.9 $1.5 \%$.

W. Mayer et al. complement the works by P. Koutroumpis and N. Czernich et al. by introducing the indicator of broadband speed into the dynamic model of economic growth in addition to penetration. As was shown by W. H. Lehr et al. [5], interaction between penetration and economic impact is probably non-linear, and the impact of the broadband Internet on GDP must be the highest at the early stage of deployment, as dearly users get the largest advantage.

Review of scientific works on the topic allows concluding that the impact of the broadband connections on the GDP growth differs in high-income and low-income countries. In the World Bank research of 186 countries, C. Z.-W. Qiang et 


\section{RESULTS}

al. conclude that for the high-income countries the additional ten broadband lines per 100 people increased GDP by $1.21 \%$, while for the low-income countries the GDP growth was by $1.38 \%$ larger for every $10 \%$ increase of penetration [6, p. 45]. Also, L. Waverman et al. stated that mobile telephone connections have significant positive impact on economic growth, which is twice as large in developing countries compared to the developed ones [7]. Research by H. G. Thompson Jr and C. Garbacz [8], H. K. Chavula [9], B. Borena and S. Negash [10], and W. Mayer et al. [11] confirm that the impact of information-communication technologies, including the broadband network, on economic growth significantly differs for high-income and low-income countries.

Up to now, the issue of the role of digital regional economy factors in providing economic growth is still unsolved. Thus, the objective of this work is to identify the presence and character of its impact of the broadband Internet on economic growth of the Russian regions

\section{RESEARCH Methodology}

Most of the above mentioned works are devoted to investment to ICT as a whole. Indeed, under modern conditions, information-communication technologies have a positive impact on economic growth. Their more intense use may testify to the high development of a country.

We estimate the impact of the broadband Internet on economic growth of the Russian Federation regions. In our research, we use the well-known model of economic growth developed by N. G. Mankiw, D. Romer, and D. N. Weil [12]. In turn, the MRW model was developed on the basis of the classical model by R. M. Solow [13]. In this model we use the Cobb-Douglas production function with the permanent scale effect:

$$
Y(t)=A(t) K \alpha(t) L \beta(t) B B \gamma(t)
$$

where $\mathrm{Y}(\mathrm{t})$ is gross regional product (GRP, denoted as $\mathrm{N} 6)$; $\mathrm{K}(\mathrm{t})$ is physical capital (denoted as OSN_F); L(t) is the number of economically active population (denoted as ECONACTIV); $\mathrm{BB}(\mathrm{t})$ is the number of organizations using the Internet (denoted as N3), and the expenditures for information-communication technologies (denoted as N4); $\mathrm{A}(\mathrm{t})$ characterizes the efficiency of using the broadband Internet and its dynamics in the studied period.

The model considered in the paper employs the data of annual reports "Regions of Russia. Social-economic indicators" of the Federal Agency of State Statistics for 2010 2016.

The work considers data on all Russian regions; thus, their number in the sample counts 80, excluding the Chechen Republic, Ingushetia, Kalmykia, the Republic of Crimea, and Sevastopol, due to incomplete data. The regression model comprises the period from 2010 to 2016. Using the regional data in the equations significantly improves the integral characteristics of the model and allows viewing the general development trends in a Russian Federation subject. Thus, the data are homogeneous and comparable.
To transfer from expression (1) to a linear regression model, we used the logarithmic function in both parts of this equation. Using the above notation, we get the formula:

$$
\begin{aligned}
& \text { LOG(N6) }=\mathrm{C}(1)+\mathrm{C}(2) * \text { LOG(ECONACTIV })+ \\
& \mathrm{C}(3) * \mathrm{LOG}\left(\mathrm{OSN} \_\mathrm{F}\right)+ \\
& +\mathrm{C}(4) * \mathrm{LOG}(\mathrm{N} 4)+\mathrm{C}(5) * \mathrm{LOG}(\mathrm{N} 3)
\end{aligned}
$$

To choose between the fixed effects model and the random effects model, we use J. A. Hausman test [14]. In this case it means that we should reject the hypothesis of the absence of individual effects and choose the hypothesis taking the individual effects into account, i. e. the fixed effects model. The equation in the fixed effects model yields well-grounded results, taking the individual effects into account.

For the in-depth study, we chose the year 2014, i. e. we create a binary variable SHALL, in which 2014 will be equal to one for all Russian regions, while all other years will be equal to zero. Thus, we check to what extent the year 2014 (the year of crisis) influences the regional GDP. When applying the fixed effects, we get the following finalized form of the regression model (see Table 1).

TABLE I. THE MODEL OF ESTIMATING THE IMPACT OF THE BROADBAND INTERNET ON THE GROSS REGIONAL PRODUCT IN THE RUSSIAN FEDERATION

\begin{tabular}{|l|c|c|c|c|}
\hline \multicolumn{1}{|c|}{ Variable } & $\begin{array}{c}\text { Coefficien } \\
\mathbf{t}\end{array}$ & $\begin{array}{c}\text { Standar } \\
\text { d error }\end{array}$ & $\begin{array}{c}\text { t- } \\
\text { criterion }\end{array}$ & $\begin{array}{c}\text { Proba } \\
\text { bility }\end{array}$ \\
\hline C & 14.40400 & 0.581893 & 24.75367 & 0.0000 \\
\hline SHALL & 0.008274 & 0.007771 & 1.064721 & 0.2875 \\
\hline LOG_ECONACTIV & 0.368201 & 0.075323 & 4.888301 & 0.0000 \\
\hline LOG_OSN_F & 0.125685 & 0.032341 & 3.886267 & 0.0001 \\
\hline LOG_N4 & 0.026475 & 0.005772 & 4.586770 & 0.0000 \\
\hline LOG_N3 & 0.167676 & 0.015893 & 10.55044 & 0.0000 \\
\hline R ${ }^{2}$ & 0.997253 & & & \\
\hline Durbin-Watson stat. & 0.949795 & & & \\
\hline \multicolumn{2}{|c|}{ Dependent variable: LOG_N6. Sample of 2010-2016 } \\
\hline
\end{tabular}

The regression model results shown in Table 1 confirm that the model is well specified. The coefficients of all external variables have high significance. The model explains over $99 \%$ of the dependent variable fluctuations. By the analysis results, it is important to note that there are constant positive elasticities of the actual gross regional product in the Russian regions according to the model variables which characterize the development of the broadband Internet in them. Besides, the coefficient of SHALL variable in the model with fixed effects appeared to be statistically insignificant; this proves that the 2014 data do not have a statistically significant influence on the regional GDP formation in 2010-2016.

In general, it should be noted that the parameters of the built models completely correspond to the specificity of the applied extended model of economic growth based on the Cobb-Douglas production function: all elasticities of independent variables are positive and less than one. The sum of GRP elasticities for all components of the broadband 
[2] L.-H. Roller, L. Waverman, "Telecommunications infrastructure and economic development: A simultaneous approach”, American Economic Review, 2001, vol. 91 (4), pp. 909-923.

Internet does not exceed one, which means that the hypothesis of the nonincreasing scale effect of the production function is confirmed.

The general result of the work is confirmation of the hypothesis that the broadband Internet influenced the economic growth at the regional level in Russia in 2010-2016. The revealed effect is positive and statistically significant. The research showed that the prerequisites of multiple regression analysis are fulfilled for the built model and the built sample model of the multiple regression is adequate; hence, it can be used for forecasting.

\section{CONCLUSIONS}

The obtained results make it possible to conclude that it is necessary to improve and accelerate the broadband Internet as one of the factors of facilitating economic growth at the regional level. Also, it should be noted that the policy of introducing digital economy in the Russian regions, aimed at developing the factors of digital economy (digital transformation), is important and topical.

In future, we plan to continue research in the area of the study in the following direction: to identify and substantiate the new indicators of the broadband Internet and their impact on the development of regional economic systems in Russia..

\section{Acknowledgment}

The work was supported by the Russian Foundation for Fundamental Research and the Republic of Tatarstan, within the framework of the research project No. 18-410-160010 pa.

\section{References}

[1] R. J. Gordon, "Secular stagnation: A supply-side view", American Economic Review, 2015, vol. 105 (5), pp. 54-59.

[3] P. Koutroumpis, "The economic impact of broadband on growth: A simultaneous approach”, Telecommunications policy, 2009, vol. 33 (9), pp. 471-485.

[4] N. Czernich, O. Falck, T. Kretschmer, L. Woessmann, "Broadband infrastructure and economic growth”, The Economic Journal, 2011, vol. 121 (552), pp. 505-532.

[5] W. H. Lehr, C. Osorio, S. E. Gillett, M. A. Sirbu, Measuring broadband's economic impact. 2006.

[6] C. Z.-W. Qiang, C. M. Rossotto, K. Kimura, "Economic impacts of broadband”, Information and communications for development 2009: Extending reach and increasing impact, 2009, vol. 3, pp. 35-50.

[7] L. Waverman, M. Meschi, M. Fuss, "The impact of telecoms on economic growth in developing countries", The Vodafone policy paper series, 2005, vol. 2 (3), pp. 10-24.

[8] H. G. Thompson Jr, C. Garbacz, 'Mobile, fixed line and Internet service effects on global productive efficiency”, Information Economics and Policy, 2007, vol. 19 (2), pp. 189-214.

[9] H. K. Chavula, 'Telecommunications development and economic growth in Africa”, Information Technology for Development, 2013, vol. 19 (1), pp. 5-23.

[10] B. Borena, S. Negash, "IT infrastructure role in the success of a banking system: The case of limited broadband access”, Information Technology for Development, 2016, vol. 22 (2), pp. 265-278.

[11] W. Mayer, G. Madden, C. Wu, "Broadband and economic growth: a reassessment”, Information Technology for Development, 2019, pp. 118.

[12] N. G. Mankiw, D. Romer, D. N. Weil, “A contribution to the empirics of economic growth”, The Quarterly Journal of Economics, 1992, vol. 107 (2), pp. 407-437.

[13] R. M. Solow, “A contribution to the theory of economic growth”, The Quarterly Journal of Economics, 1956, vol. 70 (1), pp. 65-94.

[14] J. A. Hausman, "Specification tests in econometrics", Econometrica: Journal of the Econometric Society, 1978, pp. 1251-1271.

[15] Aleksandr S. Kuznetsov. Russian Professor's meeting. Russian Journal of Physical Education and Sport. Pp. 2019, 14(1), 17-22. DOI: 10.14526/2070-4798-2019-14-1-18-24 